\title{
Analytical Performance of a FRET-Based Point-of-Care Immunoassay for the Quantitation of C-Reactive Protein in Serum and Finger Prick Capillary Whole Blood
}

\section{AUTHORS:}

Rukmini Reddy, Raj Srikrishnan, Bayda Bahur, Kevin Chon, Stefan Westin, Matthew Wong, Bright Sagoe, Kurtis Bray, Valerie Day, Larry Mimms, Michael Hale

AFFILIATIONS:

ProciseDx Inc., San Diego, CA

CORRESPONDING AUTHOR:

Michael Hale, PhD

ProciseDx Inc.

9449 Carroll Park Drive

San Diego, CA 92121

Michael.Hale@procisediagnostics.com

\section{KEYWORDS:}

Crohn's disease

C-reactive Protein

Fluorophore

FRET

Inflammatory bowel disease

Lumiphore

Point-of-care

Ulcerative colitis

\section{ABSTRACT}

Time-resolved fluorescence resonance energy transfer (FRET) provides a useful technology for immunoassay measurement of proteins, This has been used to develop an immunoassay for Creactive protein (Procise CRP'M) that provides point-of-care measurement of CRP in less than 4 minutes using $20 \mu \mathrm{L}$ of either whole blood or serum. Analytical studies of the assay on the ProciseDx ${ }^{\mathrm{TM}}$ analyzer were performed to characterize its measurement capabilities.

Sensitivity, specificity, linearity, and precision - including reproducibility of finger prick blood collection and testing, suitable for routine clinical use in a point-of-care setting were demonstrated for the CRP assay. It also showed excellent analytical agreement with a current commercial CRP test.

These results indicate the Procise CRP assay is useful for obtaining fast and accurate CRP quantitation in a point of care setting that can aid in the immediate assessment of patients' inflammatory status. 


\section{INTRODUCTION}

C-Reactive Protein (CRP) is a member of the pentraxin family of proteins, several members of which have been identified to play key roles in inflammatory response.(1.2) Measurement of blood levels of CRP has long been recognized as an important tool to aid in the assessment and monitoring of inflammatory processes in a wide variety of inflammatory diseases. $(3,4)$ CRP has been shown to quickly rise from baseline levels as part of a nonspecific "acute phase" response to inflammation. This has proven useful in the management of several disease states including infection, rheumatic diseases, and inflammatory bowel diseases. $(5,6)$ Point-of-care (POC) testing of CRP can provide convenience as well as enhanced speed of result turn-around for improved patient management. ${ }^{(7-9)}$ Thus, we undertook to develop and characterize the performance of a new point-of-care immunoassay for CRP.

\section{MATERIALS AND METHODS}

Analyzer and Assay

The ProciseDx ${ }^{\mathrm{TM}}$ analyzer has been described previously. $(10,11)$ In brief, the Procise CRP assay is a homogeneous assay that uses a fluorescence resonance energy transfer (FRET) signal to detect the presence and quantity of CRP. FRET is a process in which a donor molecule, in an excited state, transfers excitation energy through dipole-dipole coupling to an acceptor fluorophore when the two are brought into close proximity. Upon excitation at a characteristic wavelength the energy absorbed by the donor is transferred to the acceptor, which in turn emits light energy. The level of light emitted from the acceptor fluorophore is directly proportional to the degree of donor/acceptor complex formation.

The Procise CRP assay format is designed as a competitive format. A monoclonal anti-CRP antibody and exogenous CRP antigen are labeled with donor and acceptor fluorophores, respectively. The monoclonal antibody specific for CRP is labelled with the donor fluorophores and the CRP antigen is labelled with the acceptor fluorophore. Similar to other competitive assay formats, as the concentration of CRP increases a proportional decrease in the signal is observed (Figure 1).

\section{Assay Operation}

The assay reaction was started by pipetting $20 \mu \mathrm{L}$ of the blood specimen into the reaction cartridge, adding the contents of a premeasured buffer bulb, and mixing by inversion. The cartridge was then inserted into the analyzer for automatic incubation and reading (Figure 2). The instrument automatically measured and corrected for buffer volume differences (created by operator differences in dispensing) and calculated results. Results were produced in less than 4 minutes.

Establishment of Assay Calibration

Calibration was established and maintained with traceability to an international gold standard, the CRP European Reference Material - DA474/IFCC. 
Determination of Linearity

Linearity was determined by testing CRP across the assay range. Testing followed CLSI Guideline, EP17-A2 Evaluation of Detection Capability for Clinical Laboratory Measurement Procedures; Approved Guideline - $2^{\text {nd }}$ Edition and EP6-A Evaluation of the Linearity of Quantitative Measurement Procedures: A Statistical Approach; Approved Guideline.

Determination of Precision

Assay precision was evaluated by testing five CRP-spiked samples containing various concentrations of native CRP. The study was performed with 2 operators for a period of 20 days. The operators ran the 5 samples in two replicates per run, with 2 runs per day and 2 lot of reagents $(n=160$ data points per sample). Coefficients of variation (\%CV) were calculated consistent with CLSI Guideline, EP05-A3 Evaluation of Precision Performance of Quantitative Measurement Methods.

\section{Determination of Analytical Sensitivity}

Limit of Blank (LOB), Limit of Detection (LOD) and Lower Limit of Quantification (LLOQ) testing, for both serum and whole blood, was determined by testing Ten native samples across 3 days in replicates of 5 per day according the methods in CLSI guideline EP17-A2 Evaluation of Detection Capability for Clinical Laboratory Measurement Procedures, 2nd Edition.

Reproducibility of Finger Prick Blood Collection and Testing Since the Procise CRP assay can measure CRP in both serum and whole blood, including capillary whole blood collected by finger prick, the reproducibility of the finger prick blood collection and CRP measurement process was determined by collecting four finger prick blood specimens each from apparently healthy volunteers using four separate fingers (ring and middle finger from each hand), collected in single study visit. Capillary whole blood specimens were immediately tested in the Procise CRP assay and \%CV calculated for the four replicate specimens. All study subjects provided written informed consent, and the study was approved by an Institutional Review Board (IRB).

\section{Method Comparison}

The analytical agreement and correlation between the Procise CRP assay were also compared headto-head with an FDA-cleared commercial assay: Orion QuikRead go ${ }^{\circledR}$ by testing according to the CLSI guideline EP09c Measurement Procedure Comparison and Bias Estimation Using Patient Samples, 3rd Edition. Both assays were run according to manufacturer's instructions.

Serum specimens used for the method comparison were deidentified leftover clinical laboratory specimens from patients undergoing standard of care CRP testing. Statistical analysis of the agreement was assessed by Deming linear regression and Pearson correlation.

Analytical Specificity

The extent to which various potentially cross reacting and interfering substances influence the results of the Procise CRP assay was determined by testing specimens spiked with increasing concentrations of the potential interferents in the CRP quantitation. Significant interference was defined as $\pm 10 \%$ of the expected value. 


\section{RESULTS}

Analytical Sensitivity and Linearity

For serum specimens the Procise CRP assay showed an LOB, LOD, and LLOQ of 1.1, 1.5, and 1.6 $\mathrm{mg} / \mathrm{L}$, respectively. For whole blood specimens the assay showed an LOB, LOD, and LLOQ of 2.5, 3.3, and $3.6 \mathrm{mg} / \mathrm{L}$, respectively (Table 1). The linear assay range for serum was determined to be $1.3-160.8 \mathrm{mg} / \mathrm{L}$, and the linear range for whole blood was $2.6-100.6 \mathrm{mg} / \mathrm{L}$. The reportable range is 3.6-100 mg/L for both matrix types. The analytical lot-to-lot, day-to-day, and run-to-run precision of the assay over 20 days is summarized in Table 2.

Reproducibility of Finger Prick Blood Collection and Testing The reproducibility expressed as and average \%CV of replicate finger prick blood collections from individual donors followed by CRP assay after each specimen collection was determined to be $11.4 \%$. The data for individual subjects are shown in Table 3.

Method Comparison

The method comparison by Deming linear regression between the Procise CRP assay and the Orion QuikRead go ${ }^{\circledR}$ assay was $Y=0.973 X-0.040, r=0.986$ and is shown graphically in Figure 3 .

Analytical Specificity

The analytical specificity of the Procise CRP assay, as measured by interference of various potentially cross-reacting or interfering substances, did not show significant interference with assay quantitation of CRP (Table 4). Significant interference was defined as a $\pm 10 \%$ or greater shift in CRP quantitation.

\section{DISCUSSION}

CRP is predominantly produced in liver cells and is one of at least 40 proteins that participate acutely in the inflammatory response. Normally, the amount of CRP produced by hepatocytes is low $(<1 \mathrm{mg} / \mathrm{L})$, but following an acute stimulus such as inflammation, the production of CRP is rapidly increased under the influence of IL-6, TNF- $\alpha$, and IL-1 $\beta$.(13) While the function of CRP in vivo is not completely understood, CRP is a useful marker for detecting infections and inflammation due to its rapid rise and short half-life $(\sim 19 \mathrm{~h})$ and for assessing the effect of therapy on the underlying disease, as resolution of the stimulus triggering its production normalizes CRP levels.(12, 13)

Shine and colleagues were the first to show that a CRP increase can be used to differentiate IBD from functional bowel disorders. In 82 patients with chronic abdominal symptoms, 19 were diagnosed with Crohn's disease (CD), 22 with ulcerative colitis (UC), and 41 with a functional bowel disorder. All of the 19 patients with CD and $59 \%$ of the 22 patients with UC showed increases in CRP compared with none of the 41 patients with functional symptoms. (14) Schoepfer and colleagues found that CRP had a $64 \%$ sensitivity and a $92 \%$ specificity in discriminating IBD ( $n=64)$ from irritable bowel syndrome (IBS) $(n=30)$. (15) A much larger study performed by Henriksen and colleagues in Norway provided CRP data on 454 patients with UC and 200 patients with CD, which was measured at diagnosis, with follow-up at 1 and 5 years. Patients with CD were noted to have a stronger mean CRP response when compared to those with UC at diagnosis (CD $51 \mathrm{mg} / \mathrm{L}$ vs UC 18 $\mathrm{mg} / \mathrm{L} ; \mathrm{P}<0.001$ ), at 1 year (CD $51 \mathrm{mg} / \mathrm{L}$ vs UC $18 \mathrm{mg} / \mathrm{L} ; \mathrm{P}<0.001$ ) and at 5 years (CD $13 \mathrm{mg} / \mathrm{L}$ vs UC $6 \mathrm{mg} / \mathrm{L}$; $\mathrm{P}<0.001$ ) after diagnosis. Additionally, these investigators found that CRP levels at the time 
of diagnosis were related to the extent of disease in patients with UC, but no such association was found in CD.(14) Current practice guidelines from the American College of Gastroenterology recommend the measurement of $\mathrm{CRP}$ as a method to confirm gastrointestinal inflammation.(15)

The measurement of CRP represents a useful laboratory test as an aid in evaluation of infection, tissue injury, and inflammatory disorders. CRP testing shows various advantages in comparison to the erythrocyte sedimentation rate (ESR) and the leukocyte count. In fact, it is more sensitive, the increase occurs earlier and its levels return to the reference range more rapidly after healing. ${ }^{16-19)}$ In addition the point-of care testing capability provided by the FRET IVD System increases the speed and availability of accurate CRP measurements to enable faster evaluation and better management of patients with inflammatory conditions.

This study demonstrated that the Procise CRP assay provides good analytical performance, including good reproducibility of collection and testing of finger prick whole blood specimens, and excellent correlation to an existing commercial assay. These data suggest the test will be useful in POC laboratories and physicians' offices. The point of care use of this test provides convenience of location, ease of use, and quick availability of assay results that can enable faster clinical decision making -- potentially leading to better management of patients with inflammatory conditions.

Additional clinical studies will be needed to provide direct comparisons between the Procise assay results and the clinical state of patients. However, excellent analytical correlation to an assay already commercialized and in routine clinical use suggest that the Procise CRP assay will also prove to be clinically useful but with the added advantages of POC availability.

\section{ACKNOWLEDGEMENT}

The authors wish to acknowledge Manisha Yadav and Ruo Huang for their technical contributions.

\section{DISCLOSURE}

All authors are employees of ProciseDx Inc.

\section{REFERENCES}

1. Gewurz H, Zhang XH, Lint TF Structure and function of the pentraxins. Curr. Opin. Immunol. 7 (1): 54-64. 1995

2. Martinez de la Torre, Y; Fabbri, M. Evolution of the pentraxin family: the new entry PTX4. $J$ of Immunol. 184 (9): 5055-64. 2010

3. Pepys, MB, Baltz, ML Acute phase proteins with special reference to C-reactive protein and related proteins (Pentraxins) and serum amyloid A protein. Adv. Immunol, 24:141. 1983

4. Hind $\mathrm{CRH}$, Pepys MB. The role of serum C-reactive protein (CRP) measurement in clinical practice. Int Med 5:112-151. 1984

5. Slaats J, ten Oever J, van de Veerdonk FL, Netea MG (2016) IL-1ß/IL-6/CRP and IL18/ferritin: Distinct inflammatory programs in infections. PLoS Pathog 12(12): e1005973. doi:10.1371/journal.ppat.1005973 
6. Chang S., Malter, L. Hudesman, D., "Disease monitoring in inflammatory bowel disease." World J. of Gastroent. 21: 11246-11259. 2015

7. Monteny M. et al., Point-of-care C-reactive protein testing in febrile children in general practice. Clin. Chem. Lab. Med. 44: 1428-1432. 2006

8. (No authors listed) Point-of-care CRP testing in the diagnosis of pneumonia in adults. Drug Therapy Bulletin 54:117-120 2016

9. Howick J, et al. Current and future use of point-of-care tests in primary care: an international survey in Australia, Belgium, The Netherlands, the UK and the USA. BMJ Open;4: e005611. doi:10.1136/bmjopen-2014-005611 2014

10. Ong E, Huang R, Kirkland R, Westin S, Salbato J, Bray K,; et al. (2020): Therapeutic drug monitoring: performance of a FRET-based point-of-care immunoassay for the quantitation of infliximab and adalimumab in blood. ChemRxiv. Preprint.

https://doi.org/10.26434/chemrxiv.13277321.v2. 2020

11. Yadav M; Skinner M, Reddy R; Wong M,; Chon K,; Srikrishnan R; et al. (2021):

Performance of a FRET-based point-of-care immunoassay for the quantitation of fecal calprotectin. ChemRxiv. Preprint. https://doi.org/10.26434/chemrxiv.14043821.v1 2021

12. Vermeire S, Van Assche G, Rutgeerts P. Laboratory markers in IBD: useful, magic, or unnecessary toys? Gut 55(3):426-431. 2006

13. Henriksen M, Jahnsen J, Lygren I, et al. C-reactive protein: a predictive factor and marker of inflammation in inflammatory bowel disease. Results from a prospective populationbased study. Gut 57:1518-1523. 2008

14. Shine B, Berghouse L, Jones JE, Landon J. C-reactive protein as an aid in the differentiation of functional and inflammatory bowel disorders. Clin Chim Acta. 148(2):105-109. 1985

15. Schoepfer A, Trummler M, Seeholzer P, et al. Discriminating IBD from IBS: comparison of the test performance of fecal markers, blood leukocytes, CRP, and IBD antibodies. Inflamm Bowel Dis 14(1):32-39. 2008

16. Guidance for Industry - Review Criteria for Assessment of C Reactive Protein (CRP), High Sensitivity C-Reactive Protein (hsCRP) and Cardiac C-Reactive Protein (cCRP) Assays. Food and Drug Administration. September 22, 2005

17. Lichtenstein, G, Hanauer, S, Sandborn, W and the Practice Parameters Committee of the American College of Gastroenterology. Management of Crohn's disease in adults. Am J Gastroenterol online publication, doi: 10.1038/ajg.2008.168. 2008

18. Solem C, Loftus E, Tremaine W, Harmsen W, Zinsmeister A, Sandborn W. Correlation of Creactive protein with clinical, endoscopic, histologic, and radiographic activity in inflammatory bowel disease. Inflamm Bowel Dis.11:707-712. 2005

19. Mendoza J, Abreu M. Biological markers in inflammatory bowel disease: practical consideration for clinicians. Gastroenterol Clin Biol.33 Suppl 3:S158-S173 2009 


\section{FIGURES}

Figure 1. A Representation of the Procise CRP FRET Assay Format. A FRET emission signal from the acceptor is only created in the presence of CRP within the sample.

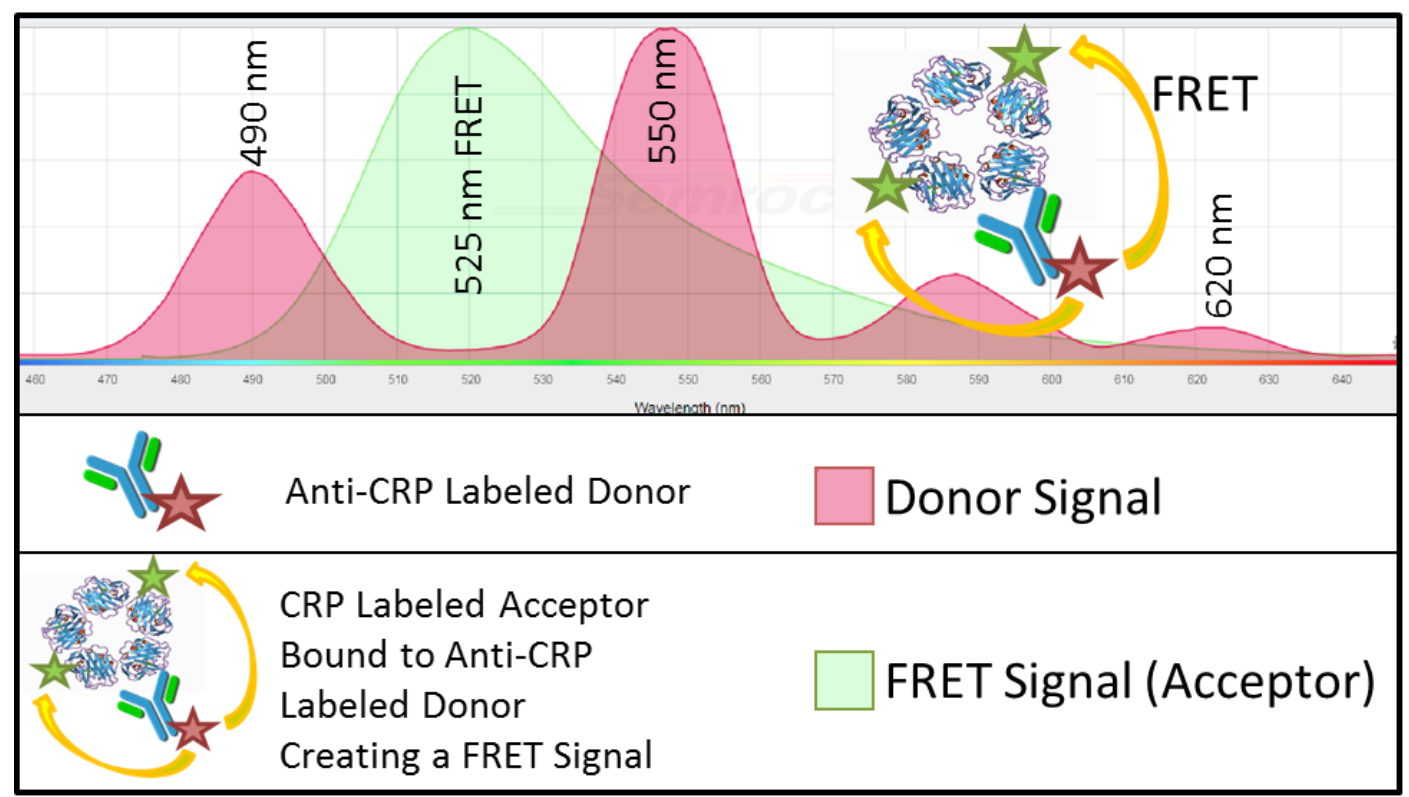

Figure 2. Summary of CRP Assay Operation and Work Flow

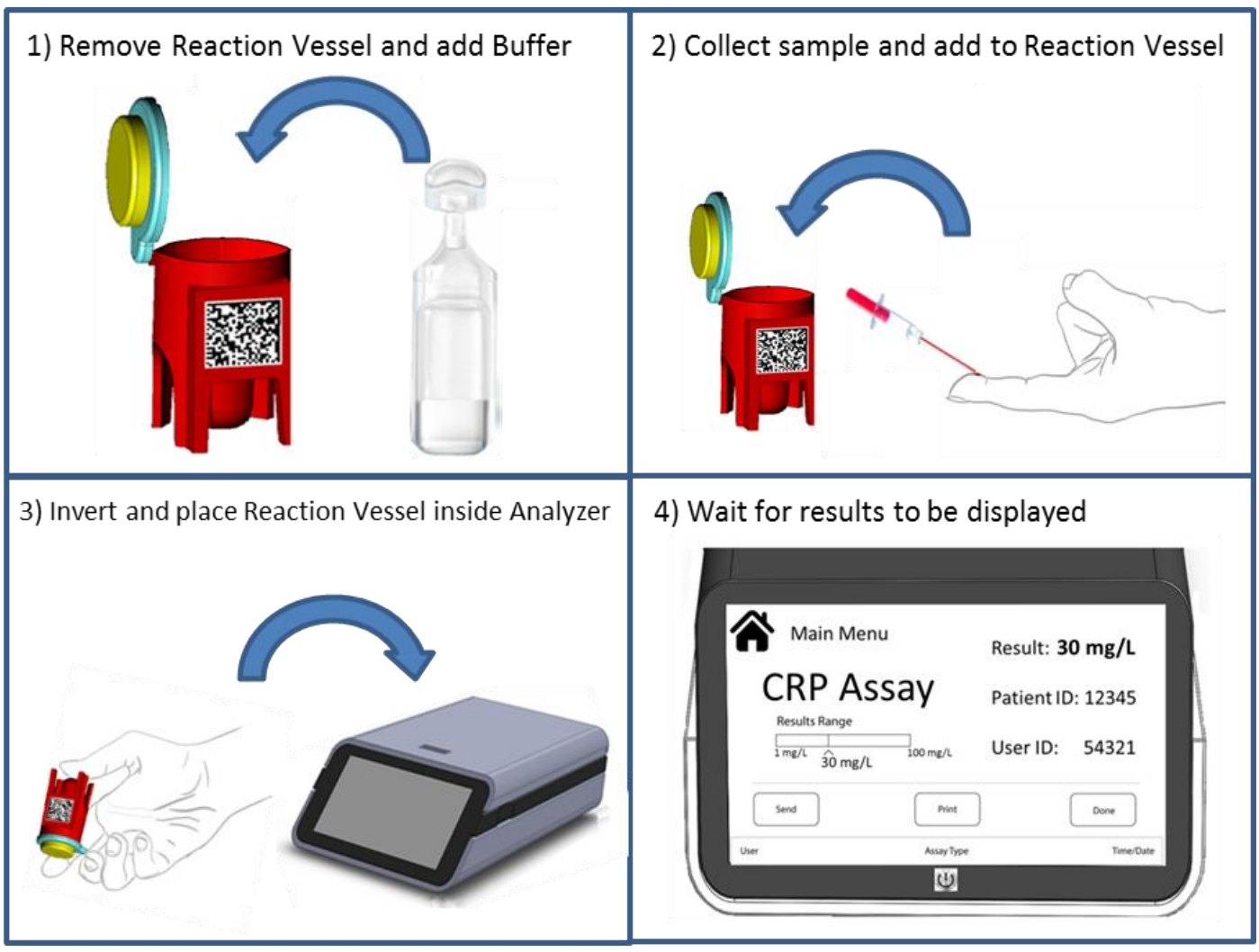


Figure 3. Deming linear regression and Pearson correlation between Procise CRP and Orion QuikRead go.

\section{Orion Serum CRP vs. Procise Serum CRP}

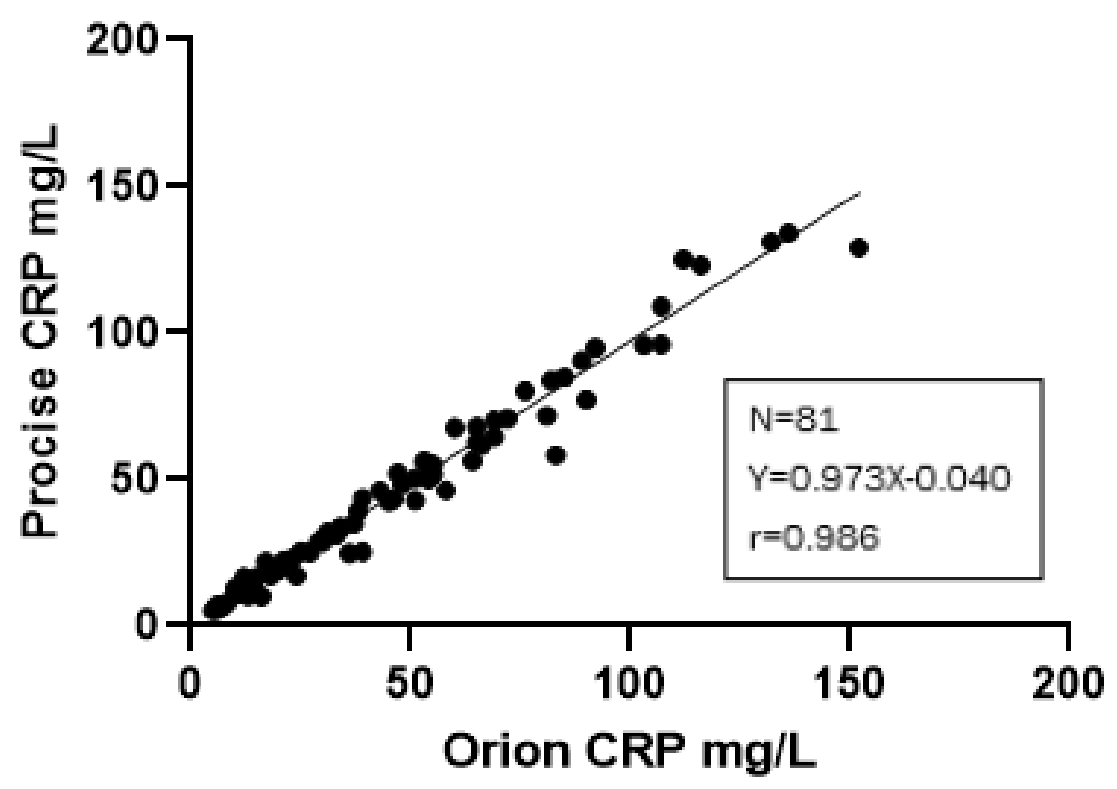




\section{TABLES}

Table 1. Analytical Sensitivity

Limit of Blank (LOB), Limit of Detection (LOD) and Limit of Quantification (LOQ) testing, for both serum and whole blood, was performed based on guidance from CLSI document EP17-A2. Ten samples containing native CRP were tested across 3 days in replicates of 5 per day.

\begin{tabular}{|c|c|c|}
\hline & Serum (mg/L) & Whole Blood (mg/L) \\
\hline LOB & 1.1 & 2.5 \\
\hline LOD & 1.5 & 3.3 \\
\hline LLOQ & 1.6 & 3.6 \\
\hline
\end{tabular}

Table 2. Precision

The lot-to-lot reproducibility of the assay was evaluated by testing five serum samples containing various concentrations of CRP. This study was performed with 2 operators for a period of 20 days. Each operator ran the 5 samples in two replicates per run, with 2 runs per day. Each operator ran a different lot of reagents. ( $\mathrm{N}=160$ data points per sample).

\begin{tabular}{|c|c|c|c|c|c|c|c|c|c|c|c|}
\hline Sample & Mean & \multicolumn{2}{|c|}{ Within Run } & \multicolumn{2}{c|}{ Between Run } & \multicolumn{2}{|c|}{ Between Day } & \multicolumn{2}{|c|}{ Between Lot } & \multicolumn{2}{|c|}{ Total } \\
\cline { 3 - 13 } & $(\mathrm{mg} / \mathrm{L})$ & SD & CV (\%) & SD & CV (\%) & SD & CV (\%) & SD & CV (\%) & SD & CV (\%) \\
\hline 1 & 5.7 & 0.3 & 4.9 & 0.2 & 3.8 & 0.1 & 1.2 & 0.2 & 3.0 & 0.4 & 7.0 \\
\hline 2 & 50.6 & 2.2 & 4.4 & 0.9 & 1.8 & 0.9 & 1.8 & 0.8 & 1.7 & 2.7 & 5.4 \\
\hline 3 & 8.7 & 0.4 & 4.7 & 0.2 & 1.9 & 0.1 & 1.3 & 0.2 & 2.1 & 0.5 & 5.6 \\
\hline 4 & 36.8 & 1.4 & 3.9 & 0.4 & 1.2 & 0.3 & 0.9 & 0.3 & 0.9 & 1.6 & 4.3 \\
\hline 5 & 71.8 & 3.6 & 5.1 & 1.1 & 1.5 & 1.4 & 1.9 & 1.1 & 1.6 & 4.2 & 5.8 \\
\hline
\end{tabular}

Table 3. Reproducibility of Finger Prick Blood Collection and CRP Testing. Four replicate blood specimens were collected from 13 subjects and tested in the CRP assay.

\begin{tabular}{|c|c|c|c|c|c|}
\hline Subject ID & $\begin{array}{c}\text { Rep 1 } \\
\mathrm{mg} / \mathrm{L}\end{array}$ & $\begin{array}{c}\text { Rep 2 } \\
\mathrm{mg} / \mathrm{L}\end{array}$ & $\begin{array}{c}\text { Rep 3 } \\
\mathrm{mg} / \mathrm{L}\end{array}$ & $\begin{array}{c}\text { Rep 4 } \\
\mathrm{mg} / \mathrm{L}\end{array}$ & \%CV \\
\hline 1 & 15.88 & 17.44 & 15.08 & 13.80 & $9.8 \%$ \\
\hline 2 & 4.11 & 3.45 & 4.43 & 4.32 & $10.8 \%$ \\
\hline 3 & 4.20 & 3.22 & 3.32 & 3.71 & $12.3 \%$ \\
\hline 4 & 1.67 & 1.86 & 1.78 & 1.89 & $5.6 \%$ \\
\hline 5 & 2.99 & 2.06 & 2.20 & 2.07 & $19.1 \%$ \\
\hline 6 & 2.18 & 2.33 & 2.74 & 2.21 & $10.8 \%$ \\
\hline 7 & 9.49 & 12.11 & 10.63 & 12.09 & $11.4 \%$ \\
\hline 8 & 2.16 & 1.94 & 1.68 & 2.27 & $12.8 \%$ \\
\hline 9 & 3.24 & 3.68 & 2.97 & 2.92 & $10.9 \%$ \\
\hline 10 & 1.76 & 1.85 & 1.99 & 1.66 & $7.5 \%$ \\
\hline 11 & 2.05 & 1.88 & No specimens collected & N/A \\
\hline 12 & 1.78 & 2.45 & 2.05 & 1.74 & $16.4 \%$ \\
\hline 13 & 1.85 & 1.72 & 2.13 & 2.04 & $9.5 \%$ \\
\hline & & & \multicolumn{5}{|c}{ Mean \%CV } & $11.4 \%$ \\
\cline { 4 - 7 } & & &
\end{tabular}


Table 4. Procise CRP Analytical Specificity

Human serum pools were supplemented with known concentrations of the drugs or blood

constituents and analyzed. Significant interference was defined as greater than $\pm 10 \%$ shift in the result for a normal range specimen.

\begin{tabular}{|l|l|l|}
\hline \multicolumn{1}{|c|}{ Interferent } & $\begin{array}{l}\text { Range of Interferent } \\
\text { Concentrations Tested }\end{array}$ & $\begin{array}{l}\text { Maximum Concentration at } \\
\text { Which No Significant } \\
\text { Interference was Observed }\end{array}$ \\
\hline Bilirubin Conjugated & $0.3 \mathrm{mg} / \mathrm{dL}-43 \mathrm{mg} / \mathrm{dL}$ & $43 \mathrm{mg} / \mathrm{dL}$ \\
\hline Bilirubin Unconjugated & $1.2 \mathrm{mg} / \mathrm{dL}-40 \mathrm{mg} / \mathrm{dL}$ & $40 \mathrm{mg} / \mathrm{dL}$ \\
\hline Hemolysate & $200 \mathrm{mg} / \mathrm{dL}-300 \mathrm{mg} / \mathrm{dL}$ & $300 \mathrm{mg} / \mathrm{dL}$ \\
\hline Triglycerides & $3.7 \mathrm{nmol} / \mathrm{L}-28.7 \mathrm{nmol} / \mathrm{L}$ & $28.7 \mathrm{nmol} / \mathrm{L}$ \\
\hline Acetaminophen & $3 \mathrm{mg} / \mathrm{dL}-20 \mathrm{mg} / \mathrm{dL}$ & $20 \mathrm{mg} / \mathrm{dL}$ \\
\hline Acetylsalicylic Acid & $40 \mathrm{mg} / \mathrm{dL}-65 \mathrm{mg} / \mathrm{dL}$ & $65 \mathrm{mg} / \mathrm{dL}$ \\
\hline Ascorbic Acid & $20 \mu \mathrm{mol} / \mathrm{L}-170 \mu \mathrm{mol} / \mathrm{L}$ & $170 \mu \mathrm{mol} / \mathrm{L}$ \\
\hline Infliximab & $5 \mu \mathrm{gm} / \mathrm{mL}-20 \mu \mathrm{gm} / \mathrm{mL}$ & $20 \mu \mathrm{gm} / \mathrm{mL}$ \\
\hline Adalimumab & $5 \mu \mathrm{mm} / \mathrm{mL}-20 \mu \mathrm{gm} / \mathrm{mL}$ & $20 \mu \mathrm{gm} / \mathrm{mL}$ \\
\hline
\end{tabular}

